\title{
Arte x Política: um debate sobre o cinema sul- americano e conservadorismo no tempo presente (2017-2019)
}

Igor Lapsky ${ }^{1}$

\begin{abstract}
Resumo: o objetivo deste artigo é analisar produções cinematográficas sul-americanas entre os anos de 2017 e 2019, considerando sua repercussão na mídia, sobretudo a partir da atuação de grupos conservadores dos países dos filmes escolhidos. Para tal, utilizamos três longas-metragens e um média-metragem que tratam de temáticas relacionadas, como religião, família e gênero, questões centrais defendidas pelos conservadores no Paraguai, Chile e Brasil. Consideramos a relação cinema e política a partir da análise do contexto político dos países com as histórias desenvolvidas. Os filmes apresentados, apesar de serem distintos, possuem elementos em comum, pois discutem as concepções tradicionais da família cristã, mas não apresentam a mesma repercussão nas mídias devido aos conteúdos abordados. Para o desenvolvimento da análise fílmica, partimos da operação de Marc Ferro para compreendermos o desenvolvimento do conteúdo latente do filme a partir do contexto político e social dos países em que os filmes foram produzidos.
\end{abstract}

Palavras-chave: Cinema, Política Sul-americana, Conservadorismo

\section{Art vs. Politics: a debate on South American cinema and conservatism in the present time (2017-2019)}

\begin{abstract}
The objective of this article is to analyze South American film productions between the years 2017 and 2019 considering their repercussion in the media, especially from the performance of conservative groups from the countries of the chosen films. To this end, we used three feature films and one medium-length film that deal with related themes such as religion, family and gender, central issues defended by conservative groups in Paraguay, Chile and Brazil. We consider the relationship between cinema and politics from the analysis of the political context of the countries with the stories developed. The films presented, although distinct, shared elements since they discuss the traditional conceptions of the Christian family, but do not present the same repercussion in the media due to the contents addressed. To develop the film analysis, we started from Marc Ferro's operation to understand the development of the latent content of the film from the political and social context of the countries where the films were produced.
\end{abstract}

\footnotetext{
1 Doutor em História Comparada pela UFRJ, Professor adjunto de História Contemporânea do Departamento de História da Universidade de Pernambuco/ Campus Mata Norte e vice-coordenador do Programa de Mestrado Profissional em Ensino de História (ProfHistória UPE). Realiza pesquisa intitulada Cultura e política nas sociedades ocidentais no mundo contemporâneo. Endereço para contato: igorlapsky@gmail.com.
} 
Keywords: Cinema, South American politics, Conservatism.

Artigo recebido em: 30/01/2020

Artigo aprovado para publicação em: 24/04/2020

\section{Introdução}

O objetivo deste texto é analisar filmes da América do Sul lançados entre 2017 e 2019, considerando a repercussão das obras na imprensa e a cobertura dos jornais sobre a reação de grupos conservadores dos países, contrária ao enredo e os personagens desenvolvidos nas histórias. Compreendemos o conceito de conservadorismo a partir de um movimento de recusa às mudanças que mantém a ordem social e política de um país (SILVA, 2000). Para desenvolvimento do artigo, escolhemos produções sul-americanas que tratam de temáticas que repercutiram na imprensa, devido aos enfrentamentos com setores conservadores dos países selecionados. Realizamos análises de produções de Paraguai, Chile e Brasil que possuem temáticas aproximadas em relação aos debates contemporâneos: a discussão sobre gênero, família tradicional e religião. Das produções de Chile e Paraguai, optamos por filmes premiados em festivais recentes entre os anos de 2018 e 2019. No Brasil, relacionamos duas produções cinematográficas de 2019 às repercussões das obras com a política contemporânea brasileira, sobretudo após a eleição de Jair Bolsonaro. Ao final, realizamos uma comparação do conteúdo dos filmes como forma de analisar a crítica desenvolvida à política dos grupos conservadores nos países trabalhados no texto.

O cinema é uma ferramenta de análise consolidada pelo historiador e demais pesquisadores das Ciências Humanas, por abordar diferentes realidades em outro tipo de linguagem e pelo seu potencial de alcance a grandes públicos (LAPSKY, 2014). Segundo Jacques Rancière (2017, p.247), "o cinema tem uma relação intrínseca com uma certa ideia de história e com a historicidade das artes a que ele é atado". Desde sua concepção, a arte cinematográfica é fruto de um complexo industrial da arte, da reprodutibilidade técnica (BENJAMIN, 2012) à indústria cultural (ADORNO e HORKHEIMMER, 1985), os filmes são 
tratados como elementos de consumo para a massa (MORIN, 2018). Partindo dessa premissa, as histórias desenvolvidas necessitam de um apelo que dialogue com as demandas do cotidiano dos espectadores.

Como desenvolvido na tese de Pierre Sorlin (1986), o cinema possibilita uma experiência de interação entre filme e plateia, que se dá a partir da identificação com a história de diversas formas. Seja pelos protagonistas, que ganharam espaço quando o cinema deixou de promover sua capacidade de inovação tecnológica para investir na complexidade das histórias e atuação dos artistas, formando o sistema de estrelato, ou pelas histórias contadas, que cativam o espectador a partir de suas experiências pessoais, o público compreende o texto ou conteúdo aparente do filme (FERRO, 2012). Partindo das discussões e da relação com o cotidiano, o espectador decifrará o subtexto ou conteúdo latente, que trata da mensagem naquele filme (idem). De acordo com Jorge Nóvoa (2009), o cinema produz representações do real, a partir das narrativas desenvolvidas na história. O filme contém questões que abordam desde a comunicação, as emoções do espectador até as interpretações pertinentes à sociedade, com potencial de elaborar teses explicativas sobre fenômenos históricos, sociais ou psicológicos.

O conteúdo latente é um elemento atrelado ao presente da obra e do espectador. Independentemente da temporalidade do filme, as discussões tratadas foram desenvolvidas e pensadas a partir de problemas contemporâneos, fazendo com que, em alguns momentos, o filme ganhe repercussão mais pela discussão em torno das temáticas desenvolvidas na história, relacionadas ao cotidiano do público, que pelo seu enredo ou qualidade. Nesse sentido, o cinema tem uma relação direta com a política (FUHRHAMMAR e ISAKSSON, 1976), consolidada ao longo do século XX, quando o aparato tecnológico do cinema esteve ligado aos fronts de batalha e as formulações de apoio às guerras, principalmente nos Estados Unidos e Inglaterra (VIRÍLIO, 2005).

Diferentemente da proposta de Ferro, que defendia a utilização de filmes documentários como fonte histórica, apresentando o teor político das produções, acreditamos que todas as produções possuem debates políticos e sociais atrelados ao 
cotidiano. Assim, mesmo os filmes de grande porte possuem fundamentação política, devido ao seu grande alcance em diversas sociedades, gerando um amplo debate (LAPSKY, 2014).

As produções latino-americanas possuem questões centrais que refletem as contradições nas sociedades, os posicionamentos políticos e projetos culturais inseridos em histórias diversificadas, que podem ou não ser atreladas diretamente a um acontecimento histórico (JUNIOR e TROVÃO, 2018). No caso dos filmes tratados no artigo, apresentam questões sociais polêmicas quando atreladas ao funcionamento da política de Brasil, Chile e Paraguai, sobretudo em relação a atuação dos grupos religiosos católicos e evangélicos.

Os grupos religiosos possuem presença significativa nas políticas dos países pesquisados. Segundo Boas (2019), Seman (2019), Melo (2018) e Lacerda (2017), o Brasil possui uma ala evangélica fortalecida pela ampla participação da construção da constituição de 1988, permitindo que os evangélicos neopentecostais se fortalecessem politicamente a partir da eleição de seus representantes, com a ideia promovida por Josué Sylvestre de "Irmão vota em irmão" (BOAS, 2019, p. 446). A atuação da "bancada da Bíblia” se dá a partir da tentativa de normatizar a sociedade em prol de seus preceitos religiosos, promovendo cultos em eventos oficiais e regulamentando os comportamentos a partir do controle das secretarias e grupos de trabalho do Governo Federal destinados à família e aos Direitos Humanos. Nesse sentido, os discursos sobre "ideologia de gênero", "família tradicional” e "cura gay" ganham força devido às alianças políticas realizadas pelos presidentes eleitos no século XXI, pois todos os candidatos negociaram e mantiveram em cargos estratégicos lideranças evangélicas de discursos radicais e normativos em relação à sociedade.

No Chile, Boas (2019) afirma que a força dos evangélicos é menor no país, mas ela é substituída pela presença dos católicos nos cargos públicos. Tais lideranças mantém um posicionamento conservador atrelado à economia (como a defesa do livre-mercado e o estado mínimo), e poucas intervenções nas questões sociais. Porém, há questões que 
foram encaminhadas em lento processo com o presidente Sebastián Piñera, forçado a adotar medidas mais populares como a Lei de Identidade de Gênero, alteração da regra da previdência e a redução do preço do transporte público por causa das manifestações populares ocorridas em 2019. Além disso, há de se considerar personagens como José Antônio Kast, do Partido Republicano ${ }^{2}$, candidato à presidência em 2018 considerado o "Bolsonaro chileno", que critica o aborto e defende o ex-presidente Augusto Pinochet (EL PAÍS, 2017).

O Paraguai possui forte influência católica na política, culminando com a eleição de um ex-bispo para presidência do país. De acordo com Pablo Ortiz, jornalista do ABC Color, "o Paraguai não é um estado laico, mas deveria respeitar a liberdade de religiosa e de culto, algo que não faz" (2019). As atuações de governadores e representantes dos cargos do governo federal são pautadas em preceitos religiosos, em especial o Ministro da Educação, que defende a homossexualidade como uma enfermidade (idem).

Segundo Cristian Gumucio (2012, p. 20), há uma corrente cristã conservadora na América Latina que não se apresenta uníssona, visto que há o catolicismo e movimentos que ganharam força nos últimos anos, tais como protestantes, evangélicos apolíticos e abstencionistas. Apesar de possuir diversas frentes, elas se unem em prol das "questões morais", como a luta contra o aborto e o matrimônio homossexual.

As questões morais defendidas pelos grupos conservadores de Brasil, Chile e Paraguai são criticadas nos elementos dos filmes escolhidos. Apresentamos a discussão dos filmes a partir de dois blocos: a discussão sobre gênero, tratada por Uma Mulher Fantástica, As Herdeiras e A Primeira Tentação de Cristo; e um segundo bloco destinado à família, religião e funcionamento do Estado, em que é apresentado o longa-metragem Divino Amor. Optamos por fazer uma análise de sequências importantes dos filmes para

\footnotetext{
${ }^{2}$ Nos princípios do partido, há destaque para a defesa da família e o reconhecimento da união entre homem e mulher como a única forma de matrimônio. Para mais, ver: PARTIDO REPUBLICANO. Princípios. Disponível em: https://www.partidorepublicanodechile.cl/principios Acesso em 20 abr 2020.
} 
fortalecer os seus argumentos, visto que são elementos relacionados aos pontos de crítica ao analisarmos a repercussão dos filmes.

\section{Uma Mulher Fantástica, As Herdeiras e A primeira tentação de Cristo: um debate sobre gênero e conservadorismo}

O cinema sul-americano lançou diversas produções que tratam da questão de gênero nos últimos anos. Boa parte delas tiveram repercussões em seus países por abordarem questões sensíveis às sociedades dos países, devido à apresentação de casais homossexuais, protagonistas transsexuais e remontagens históricas abordando a sexualidade como um dos elementos centrais. É o caso dos filmes debatidos nesta seção: Uma Mulher Fantástica (Una mujer fantastica, Sebastian Lelio, Chile, 2017, 104 min), As Herdeiras (Las Herdereras, Marcelo Martinessi, Paraguai, 98 min) e A primeira tentação de Cristo (Rodrigo Van der Put, Brasil, 2019, $46 \mathrm{~min}$ ) apresentam questões que repercutiram de modos distintos em seus países.

O primeiro filme debate as questões relacionadas à condição dos transsexuais no Chile. Conta a história de Marina (Daniela Vega), uma garçonete e cantora que tem um relacionamento com Orlando (Francisco Reyes), que após uma noite romântica de comemoração, sofre um AVC e morre no hospital. A tragédia para Marina é desenvolvida ao longo do filme: além de perder o homem que amava, ela precisa lidar com os preconceitos que um transsexual passa no cotidiano.

O segundo retrata a história de um casal de duas mulheres, Chela (Ana Brun) e Chiquita (Margarita Irun), herdeiras de famílias abastadas de Assunção que vivem juntas há 30 anos. A situação financeira do casal começa a piorar, fazendo com que elas tenham de vender suas propriedades para se manterem, até que Chiquita é acusada de fraudes contra o banco da cidade. Tal situação força Chela a mudar seus hábitos do cotidiano, fazendo com que ela mude seu comportamento e sua percepção da vida.

O terceiro trata da história de Jesus (Gregório Duvivier), que, ao fazer 30 anos, volta de sua peregrinação pelo deserto e leva um companheiro (Fábio Porchat) para sua festa de aniversário. Diversos elementos no filme são abordados: o principal deles é 
mostrar um Jesus homossexual, que apresenta seu companheiro a sua família; o segundo é a relação entre Maria (Evelyn Castro), José (Rafael Portugal) e Deus (Antônio Tabet), que se desenvolve no filme a partir de conotações sexuais, José e Deus em uma relação tensa por Maria, em uma espécie de "Dona Flor e seus Dois Maridos".

No longa-metragem chileno, a protagonista passa todo o filme lutando por reconhecimento e o direito de velar o corpo de seu amante. As dificuldades de Marina começam no hospital, quando é interrogada pela enfermeira:

- (ENFERMEIRA) "Você é membro da família?"

- (MARINA) "Não, só o trouxe aqui."

- (E) "Você não o conhece?"

- (M) "Sim, somos amigos"

Marina, para evitar os olhares de interrogação da enfermeira, decide renunciar naquele momento a sua condição de mulher de Orlando. Ela se rebaixa à condição de "amiga", que "somente o trouxe até ali". O espectador visualiza, segundos antes do diálogo retratado acima, que a enfermeira sai da sala com os pertences de Orlando com um olhar desconfiado, sendo enfática nas perguntas, como se ela soubesse que Marina era mais que uma amiga, desafiando-a a responder sobre seu parentesco com o homem.

A segunda dificuldade aparece logo depois de a enfermeira se retirar da sala, quando o médico socorrista vai ao encontro de Marina para conversar sobre a situação de Orlando:

- (MÉDICO) "Você é da família do Sr. Onetto?"

- "Sou"

- "É companheira dele?

- "Sim, somos companheiros"

- "Perdão, seu nome é?"

- "Marina Vidal"

- Mas, não é um pseudônimo?"

Após a pergunta realizada pelo médico, Marina é convidada a se dirigir a uma parte do hospital, na qual é informada que Orlando acabara de falecer. Ao notar o problema, ela foge do local, pois saberia que seria necessário explicar o ocorrido para as 
autoridades, uma vez que médico e enfermeira questionavam a presença dela ali e como ela havia trazido Orlando para o socorro. No meio da rua, Marina é detida por um carro de polícia, que a leva de volta ao hospital, onde está o terceiro problema (em pouco mais de 10 minutos decorridos de ele ter passado mal): o policial, que havia sido chamado pelo hospital para recolher o depoimento de Marina e investigar o ocorrido. Ao encontrar com o médico e o policial, Marina diz: "não precisava ter me tratado como uma criminosa". $\mathrm{O}$ olhar de desprezo do médico se dá por segundos em uma parte silenciosa da cena. $\mathrm{O}$ silêncio é quebrado pelo médico, que desvia o olhar de Marina e se direciona ao policial: "com licença, vou deixar que faça seu trabalho". O policial, então, começa o seu trabalho:

- (POLICIAL) "Senhorita, preciso dos seus dados"

- "Aqui?"

- "Aqui."

- "Nome completo?"

- "Marina.."

"Tem algum documento de identidade com você?"

- "Meu novo documento ainda não está pronto, senhor"

- "Até que o receba, este ainda é seu nome legal"

O policial passa a questionar Marina, sempre partindo do masculino. Tal ação retira a individualidade dela, pois o policial a força a se negar enquanto mulher para assumir sua identidade de nascimento.

As seguintes dificuldades passadas por Marina no longa-metragem são relacionadas à questão da família de Orlando. A ex-esposa, Sonia (Aline Küppenheim), e o filho Gastón (Nesto Cantillana) impõem à Marina que sejam devolvidos os pertences do marido: primeiramente o carro, depois o apartamento. A negação dos pertences é tamanha que Gastón, ao conversar com Marina, solicita que diabla, a cadela, seja devolvida a ele, mesmo sendo apresentado na cena sua falta de amor pelo bicho. Tais questões são problemas que foram abordados de outra forma pelo cinema e outros materiais audiovisuais, como novelas e seriados, mas que no filme são aprofundadas pela condição de Marina: Sônia a trata como uma “aberração", enquanto Gastón a ameaça em uma cena na qual a aborda com os amigos em um carro e a leva a um local distante da 
cidade, prende sua cabeça com fita adesiva, afirmando que Marina deveria ficar longe do velório e da família.

As dificuldades de vivência também são apresentadas no longa-metragem paraguaio, porém de forma distinta. Chela e Chiquita são mulheres homossexuais acima dos 50 anos, não têm filhos e nem uma estrutura familiar definida aos moldes da política tradicional paraguaia. Elas possuem propriedades e uma relação estabilizada, que é rompida ao sabermos que serão separadas devido a um processo judicial de sonegação de impostos, em que Chiquita será condenada ao cárcere.

Destacamos a ausência de homens na condução da história. Percebemos isso em diversos trechos: o início, em que mostra as mulheres fazendo negociação sobre os itens que estão sendo vendidos, a festa em que Chela e Chiquita comparecem, na qual não há homem presente. Os homens aparecem em poucas situações e em posições secundárias: na cena do encarceramento de Chiquita, o homem presente é subalterno da agente penitenciária; os carcereiros responsáveis pela abertura dos portões funcionam sob ordens de mulheres; os carregadores do piano adquirido atendem as ordens da jovem que comprou o móvel e mandou carregar o caminhão.

As mulheres são apresentadas em práticas do cotidiano associadas comumente nos filmes à figura masculina: as senhoras se reúnem para, em vez de tomarem chá e fazerem compras, jogarem cartas; as mulheres, de passageiras, são motoristas; de dona de casa passam à dona da casa. As cenas, realizadas de forma bem sutil, são apresentadas com naturalidade no filme.

O filme apresenta o argumento que mesmo em uma relação homossexual há problemas de relações de poder comumente apontadas aos casais heterossexuais. Tal questão é vista a partir da vida de Chela e Chiquita. Antes da prisão, Chiquita era a motorista, a pessoa que conduzia os rumos da casa, e Chela, depressiva e entregue às pílulas do dia-a-dia, era carregada, sem o controle de sua vida emocional e financeira. A prisão de Chiquita permite Chela viver, descobrir o papel de "ser motorista" e experimentar a liberdade, seja dirigindo na autoestrada, algo apresentado como proibido 
para mulheres no filme, seja renovando seu visual e aparência, muito pelo fato de uma figura mais jovem, Angy (Ana Ivanova), desejada por Chela.

A relação entre Chela e o carro é a de maior destaque do filme. Ser motorista permite Chela a se definir como pessoa e realizar suas escolhas. Ao perceber que sua vida retornaria ao marasmo anterior, com Chiquita dirigindo, Chela opta por ser livre dos remédios, das dificuldades financeiras e, principalmente, da relação de opressão do início da história.

Em A primeira tentação de Cristo, o elemento central da história é o fato de que Jesus é apresentado como homossexual. Jesus retorna depois de sua peregrinação com um parceiro para apresentar à família, que recebe a notícia com surpresa. O parceiro amoroso de Jesus, ao longo da história, se revela como o diabo, que estava em formato de homem para seduzir o filho de Deus. A revisão da história de Jesus é um elemento que havia sido trabalhado pelo grupo Porta dos Fundos em anos anteriores, como em 2018, quando produziu outro média-metragem que satirizava o filme norte-americano Se beber não case! (The Hangover, Todd Phillips, EUA, 2009, $100 \mathrm{~min}$ ). O especial de 2018, intitulado Se beber não ceie (Rodrigo Van der Put, Brasil, 44 min) mostrava um Jesus que desaparece depois da Santa Ceita. Os apóstolos, de ressaca, devem procurá-lo.

Os três filmes tiveram repercussões em seus países. Uma Mulher Fantástica e As Herdeiras, por terem maior visibilidade internacional devido às suas participações em festivais de cinema, tiveram maior amplitude política em seus debates, enquanto A primeira tentação de Cristo ficou restrito à distribuição da Netflix e sofreu duros ataques da comunidade religiosa no Brasil.

A história de Marina em Uma Mulher Fantástica faz parte do contexto do Chile, que, ainda no segundo governo de Michelle Bachelet (2014-2018), do Partido Socialista, discutia a formulação da lei de Identidade de Gênero, que permita a pessoas se reconhecerem da melhor forma, podendo alterar seus documentos conforme a necessidade. Em 2017, ano de lançamento do filme, Bachelet lançou um projeto de lei que atenderia aos direitos das pessoas se reconhecessem nos gêneros em que achassem 
melhor. Para tal, foram lançados alguns pontos centrais, que defendiam os direitos das pessoas transsexuais, argumentando que a situação não era um problema de saúde e reforçando a igualdade de dignidade e direito de todos ${ }^{3}$. Nesse sentido, a ênfase na questão do nome e da condição de Marina está relacionada à recusa no Chile em reconhecer a identidade dos transsexuais.

O filme chileno participou e ganhou prêmios nos principais festivais de cinema pelo mundo, culminando com o Oscar de melhor filme estrangeiro em 2018. Após a vitória, o filme teve grande repercussão no país, principalmente pelo debate sobre a promulgação da lei de Identidade de Gênero. O presidente eleito, Sebastian Piñera, embora tenha parabenizado os produtores do filme ${ }^{4}$, demorou a aprovar a lei, que foi promulgada em novembro do mesmo ano. Piñera segue as bases de seu partido, o Renovación Nacional (RN), que no ponto 2 dos seus princípios defende a família como núcleo fundamental da sociedade:

\begin{abstract}
A família deve ser promovida, protegida e fortalecida, pois é o núcleo fundamental da sociedade, a principal fonte de coesão social e a rede de segurança mais confiável para as pessoas.

O Estado deve fortalecer a família, abordando seus problemas e oferecendolhes oportunidades em condições de equidade, levando em consideração o treinamento e o cuidado de crianças, encargos familiares, proteção durante a gravidez e compatibilidade entre família e trabalho, para que o ambiente de trabalho também responda às necessidades do mundo da família. ${ }^{5}$
\end{abstract}

Ao analisarmos os pontos apresentados pelo partido, percebe-se que não há espaço para outro modelo de família que não seja a patriarcal. A preocupação com a gravidez e o cuidado com as crianças, desconsiderando as questões que se referem a casais

\footnotetext{
${ }^{3}$ A plataforma do governo foi lançada para promoção da discussão, estabelecendo um histórico da luta da comunidade LGBT, buscando conscientizar as pessoas sobre a condição dos homossexuais e transsexuais. Para mais, ver: https://www.gob.cl/identidaddegenero/ Acesso em 20 dez. 2019.

${ }^{4}$ Sua postagem no Twitter parabenizando o filme foi bastante criticada pelos usuários da rede social, pois alegaram que o presidente eleito não estava sendo verdadeiro em sua manifestação, recebendo diversas mensagens que remetiam a sua posição contrária a Lei de Identidade de Gênero durante o ano de 2017. Para mais, ver: Las Reacciones a la felicitación de Sebastián Piñera para "Uma Mujer Fantástica" La Nación. Disponível em: http://lanacion.cl/2018/03/05/las-reacciones-a-la-felicitacion-de-sebastian-pinerapara-una-mujer-fantastical Acesso em 20 dez. 2019.

${ }_{5}^{5}$ Os pontos podem ser vistos em: RENOVACIÓN NACIONAL. Declaración de Principios de Renovación Nacional. Disponível em: http://www.rn.cl/principios-rn/ Acesso em 20 dez. 2019.
} 
homossexuais. Nesse sentido, a visão de família e do indivíduo reside no modelo binário de gênero. Tal elemento vai de encontro às propostas da Lei de Identidade de Gênero, uma vez que possibilita ao indivíduo se reconhecer da forma que desejar, sem discriminação ou relações patológicas. O posicionamento se corrobora com o argumento de Piñera em relação à lei: reconhece a necessidade, mas afirma que tal condição de "disforia" pode evoluir a partir de "sintomas" e se definir na etapa da adolescência, e, portanto, não deveria ser aberta para menores de idade (COOPERATIVA.cl, 2018).

As Herdeiras, assim como Uma Mulher Fantástica no Chile, vai na contramão da política paraguaia ao destacar as relações sociais e, principalmente, as de gênero, pauta que não é debatida pelos principais partidos do país. Os colorados, partido vencedor das eleições de 2018 e dominante na política paraguaia desde a segunda metade do século XX (SADER, 2006), não tem como pauta a defesa dos direitos dos homossexuais, tampouco apresenta debates sobre gênero em sua plataforma, que reforça a família tradicional como um dos elementos a serem defendidos pelo Estado.

O filme paraguaio participou de festivais internacionais e ganhou repercussão com nomeações como no Festival de Berlim, Athenas, Cartagena e Gramado, com destaque para as categorias melhor filme estrangeiro, melhor diretor e melhor atriz. No Paraguai, ele é destacado pelos feitos internacionais e apontado como uma tentativa de reconstrução da identidade do cinema do país (ULTIMA HORA, 2019). Porém, também sofre críticas de políticos alinhados à pauta conservadora no país: a senadora do PLRA (Partido Liberal Radical Autêntico), Zulma Gómez, criticou a homenagem ao filme e seu diretor realizada pelo senado, alegando que era um "filme de lésbicas" (ULTIMA HORA, 2018), e os senadores do Partido Colorado se retiraram da sessão sem participarem da homenagem. O coletivo Somos Gay denunciou a ação da senadora criticando sua posição violenta e antidemocrática:

A atitude violenta da senadora liberal Zulma Gómez não pode ser impune ao constituir um explícito discurso de ódio que não só fere a dignidade da equipe artística e técnica do filme "As Herdeiras" como constrangimento internacional como também impacta diretamente nas vidas dos habitantes do 
país ao fomentar a violência e estabelecer claramente que um segmento da nossa população não é sujeita de direitos. (SOMOSGAY, 2018. Tradução nossa).

O debate sobre gênero e a proliferação do discurso do ódio dos críticos também foi um dos elementos da repercussão do filme do Porta dos Fundos. Lançado em 03 de dezembro de 2019, católicos e evangélicos, deputados e juízes se posicionaram contrários ao filme. Os grupos religiosos elaboraram um abaixo-assinado de boicote ao filme e à Netflix, que no dia 11 do mesmo mês havia atingido cerca de 710 mil assinaturas (R7, 2019). O argumento é apresentado da seguinte forma:

Pela proibição da veiculação do filme de Natal do "Porta dos fundos", que tem
como título "A primeira tentação de Cristo". Pela remoção do filme do catálogo
da Netflix e para que o Porta dos fundos seja responsabilizado pelo crime de
vilipêndio à fé. Também desejamos uma retratação pública, pois ofenderam
gravemente os cristãos. ${ }^{6}$

A discussão sobre a reprodução da imagem de Jesus no filme foi pauta de discussão em Brasília, na Câmara dos Deputados, na qual o deputado Júlio Cesar Ribeiro, do partido Republicanos, apresentou um requerimento para a Netflix se pronunciar sobre a produção do Porta dos Fundos (ESTADO DE MINAS, 2019). Além da esfera legislativa, o judiciário também se manifestou contra o filme, primeiramente com uma tentativa de processo contra a Netflix (DIREITONEWS, 2019), depois com a ordem de suspensão do filme (ÉPOCA, 2020), revogada pelo Supremo Tribunal Federal.

As seguidas críticas e ataques ao filme e seus produtores se agravaram em 24 de dezembro de 2019, quando a sede do grupo foi atacada e sua fachada incendiada. No dia seguinte, foi disponibilizado um vídeo do YouTube do grupo intitulado "Comando de Insurgência Popular Nacionalista da Grande Família Integralista Brasileira", com discurso reivindicando a autoria do ataque, apresentando críticas à justiça brasileira, ao

\footnotetext{
${ }^{6}$ O abaixo-assinado eletrônico tem uma tradução simplificada para o inglês, com intuito de ganhar repercussão internacional, acompanhado de comentários de apoio à moção, com argumentos de ofensa e preconceito religioso. Disponível em: https://www.change.org/p/netflix-especial-de-natal-porta-dosfundos?recruiter $=1026784052 \& u t m \_s o u r c e=$ share petition\&utm campaign $=p$ sf_combo share abi\&utm medium $=$ whatsapp\&recruited by $\mathrm{id}=7 \mathrm{ff} 109 \mathrm{a} 0-1 \mathrm{c} 3 \mathrm{c}-11 \mathrm{ea}-\mathrm{b} 04 \mathrm{~b}-$ d38958a0f0e7\&utm_content=washarecopy_19374572_pt-BR\%3Av5 acesso em 14 jan. 2020.
} 
Porta dos Fundos e às influências "burguesas" e do "marxismo cultural" que levaram à produção do filme $e^{7}$.

Os três filmes debatem a questão do gênero em perspectivas distintas. Sua repercussão, principalmente nos casos paraguaio e brasileiro, se deu na negação do que estava sendo apresentado para a sociedade. $\mathrm{O}$ caso chileno acompanhou um debate em torno da demora na aprovação de legislações que protegessem o direito dos homossexuais e transsexuais. Esse fato se dá devido à visão binária da sexualidade pelas lideranças políticas e grupos religiosos desses países. Tais grupos defendem normas de comportamento em prol da "família tradicional", promovendo uma concepção rígida do gênero.

A tentativa de regulamentação de gênero não é exclusiva dos grupos conservadores da América do Sul. Segundo Joan Scott (2012), países como França, que possuem uma política bem definida em relação ao gênero, e órgãos internacionais ligados aos Direitos Humanos, têm dificuldade de debater o tema. Ela define gênero como “(...) a prática social e cultural que é o objeto de estudo - uma tentativa de amenizar as ansiedades coletivas sobres os significados da diferença sexual, de fixar estes significados, necessariamente imprecisos, de uma vez por todas" (p. 346).

De acordo com Judith Butler (2014),

Gênero é o aparato pelo qual a produção e a normalização do masculino e do feminino se manifestam junto com as formas intersticiais, hormonais, cromossômicas, físicas e performativas que o gênero assume. Supor que o gênero sempre (...) significa as matrizes "masculino" e "feminina" é perder de vista o ponto crítico que essa produção coerente e binária é contingente (...) e que as permutações de gênero que não se encaixam nesse binarismo(..). (BUTLER, 2014, p. 253).

Partindo de Scott e Butler, os filmes tratam de forma adequada a questão de gênero, uma vez que defendem uma visão não-binária relacionada ao comportamento

${ }^{7}$ Vídeo disponível em: https://www.youtube.com/watch?v=3h0cDbFOmzQ Acesso em 14 jan. 2020. 
sexual. Os argumentos de crítica aos filmes são embasados em artifícios religiosos, sobretudo no Brasil.

\section{Religião, Estado e família: Divino Amor é uma utopia?}

A questão religiosa é o tema central da produção brasileira Divino Amor (Gabriel Mascaro, Brasil, 2019, $101 \mathrm{~min})$. O filme se passa no Brasil em 2027 e conta a história de Joana (Dira Paes), uma escrivã que trabalha em cartório, no setor de divórcios. Ela é uma devota religiosa e sempre tenta convencer os casais a desistirem da separação. $O$ convencimento se dá a partir de diversas formas: conversa com o casal para novas tentativas, indica um grupo religioso para tentativa de reconciliação e, em casos extremos, atrasa as solicitações com a burocracia no cartório.

As formas de convencimento são pontos a serem debatidos no filme: há uma dificuldade de separação entre público e privado, a burocracia é a vilã da história, e a religião pauta comportamentos e todo o cotidiano de Joana e as pessoas que se relacionam com ela. Nesse sentido, a funcionária do cartório é uma burocrata, que utiliza de questões pessoais para atender o público: ela decide se os processos serão homologados a partir de requisitos parciais. Joana se encaixa no perfil das críticas ao funcionalismo público, um burocrata, que não dá andamento aos processos, corrupto, pois exerce seu trabalho de forma parcial, em benefício próprio (no caso do filme, promover sua fé). Tal discurso está em consonância com a matéria do Correio Braziliense (2018), a qual apresenta a burocracia dos países da América Latina como um dos maiores entraves ao andamento dos processos dos cidadãos. Na matéria, é veiculado o discurso de que o brasileiro perde tempo com a burocracia do serviço público, que ainda possui uma alta quantidade de etapas presenciais, que fazem a pessoas levar 5,5 horas para realização de um procedimento. Além disso, a reportagem enfatiza a questão de o brasileiro ter de voltar mais de três vezes para realizar procedimentos, apontando que o país está acima da média de casos dessa natureza na América Latina. 
Joana também representa a classe de funcionários públicos de cargos temporários, eleitos pelo povo. Sua atuação na história, a confusão entre público e privado, é um elemento recorrente na política brasileira, pois de acordo com Boas (2019), Seman (2019), Melo (2018) e Lacerda (2017), líderes religiosos evangélicos, desde a constituinte entre 1987 e 1988, estão assumindo papeis preponderantes no poder legislativo e em cargos estratégicos, trazendo seus rituais para dentro de uma estrutura que, constitucionalmente, é laica, como os cultos realizados no Palácio do Planalto (R7, 2019). É importante frisar que tais grupos foram uma das bases de apoio para a eleição do presidente Jair Bolsonaro, e continuam demandando mais espaço, como um assento no Supremo Tribunal Federal (G1, 2019).

A religião pauta toda a sociedade brasileira no filme. O carnaval deixa de ser a principal festa do país, que se torna a "festa do amor supremo", uma celebração da espera pelo retorno do Messias. Há um confessionário drive-thru no qual os fiéis em seus carros conversam com um pastor, que orienta e toca louvor para que as pessoas saiam do local purificadas. Há uma cena na qual Joana lê a regra de "divórcio consensual" para um homem no cartório: o documento apresenta que após 5 anos de casados, se não há fillhos gerados ou bens a partilhar, o divórcio é imposto ao casal, e eles deverão buscar a reconciliação a partir de aspectos legais. Nesse sentido, a estrutura burocrática do estado brasileiro em 2027 regula que os casais têm a procriação como objetivo principal, invalidando qualquer laço de casal que não cumpra a regra. Assim, o casamento entre homossexuais é excluído da história e não pode ser legitimado pelo Estado (não há homossexuais no filme).

No filme, Divino Amor $^{8}$ é um grupo de orientação de casais em crise do qual Joana e seu marido Danilo (Julio Machado) fazem parte há dois anos. Os rituais do grupo

\footnotetext{
${ }^{8}$ Na realidade, Divino Amor é um site de relacionamentos lançado em 1995, que impulsionou a indústria de relacionamentos online em diversos países. Para mais informações, ver: https://www.divinoamor.com.br/help/aboutus.aspx?lid=4 Acesso em 21 jan. 2020. Ao realizarmos uma busca no Google, as duas primeiras páginas relacionadas são o site apresentado e um site de relacionamento cristão (Amor em Cristo), que ao analisarmos, apresenta o perfil da pessoa, com uma aba específica para "Minha Religiosidade", em que são apresentadas as denominações (de qual igreja faz parte), estilo,
} 
são um destaque da história, uma vez que Joana os utiliza para convencer os casais em processo de divórcio a continuarem juntos. Há uma ênfase em três elementos centrais: o uso dos corpos, a divisão do amor e a semeadura do amor divino. O slogan do ritual é "Quem ama não trai, quem ama divide", e nesse momento é apresentado ao espectador um suingue, em que o amor é dividido e compartilhado, com uma única regra: a semente do amor, a ejaculação do marido, só pode ser em sua esposa. Os casais convencidos por Joana e Danilo enviam um porta-retrato com uma foto para a residência deles, posto em um ambiente específico da casa, que funciona como um misto de sala de oração e sala de troféus, pois cada casal convertido é uma vitória para Joana, que continua utilizando da máquina burocrática para propagar sua fé.

O modelo de família tradicional também é destacado no filme. Em cada prédio público, há um detector que indica o estado civil da pessoa, e, caso a mulher esteja grávida, se o feto está registrado no sistema de controle do estado, acompanhado da seguinte mensagem: “gravidez registrada. É mais proteção para sua família”. Se o feto não estiver registrado, o aparelho dá uma mensagem de alerta, como se a pessoa estivesse em condições ilegais. Todo o processo é monitorado por agentes públicos, que acompanham a passagem das pessoas pelo detector.

A gestante é outro elemento central da história. O assento preferencial é uma poltrona massageadora, enquanto o assento dos demais, incluindo idosos, é uma cadeira de plástico dura, enfileirada, bem desconfortável comparada ao espaço da gestante. Como o Brasil é um país apresentado com "esperança no futuro", a grávida representa as novas gerações, o futuro do Brasil. Assim, ela é um ser imaculado, puro, desde que o feto seja devidamente registrado dentro da estrutura burocrática do Estado.

A reviravolta da história se dá em dois momentos centrais: o primeiro é quando Joana é alocada de função no cartório por causa da denúncia de uma das pessoas atendidas que teve o processo de divórcio retardado pela protagonista. Nesse momento, ela perde a

importância da religião e frequência na igreja. Para mais, ver: https://www.amoremcristo.com/ Acesso em 21 jan. 2020. 
capacidade de convencimento de novos casais, visto que não poderá mais resolver os casos de divórcio, e consequentemente a possibilidade de propagação de sua fé pela máquina burocrática. O segundo momento é quando Joana descobre a gravidez, acreditando que o milagre divino fez com que Danilo, que realizava métodos clínicos e uso de equipamentos para combater a infertilidade, finalmente a engravidasse. Porém, ao consultar o exame genético no computador do cartório, ela descobre que Danilo não é o pai, causando uma crise em seu casamento, que leva à separação e à sua expulsão do Divino Amor.

A cena da conversa entre o pastor do drive-thru e Joana sobre a gravidez mostra a negação de um filho bastardo pela estrutura religiosa apresentada no filme. O pastor insiste que Joana está arrependida ou pode estar cometendo uma blasfêmia. A forma de se dirigir do pastor muda com o problema apresentado: ele vai encaminhar, "como protocolo", a questão ao "centro de atendimento ao fiel", como se a religião fosse um meio comercial, que possui um serviço para resolver problemas dos "clientes". Ao negar a ida ao Centro de Atendimento ao Fiel, Joana agora é uma desgarrada da religião, rejeitada pelo pastor que antes a atendia e lhe dava conforto.

A repercussão de Divino Amor na imprensa foi pautada no papel da religião na história e como o país é fundamentado em regras cristãs. Andres Rodríguez, articulista do El País, defende a ideia de que o filme é uma alegoria de um país "futurista, conservador e evangélico" (2019). O autor relaciona o filme ao panorama político do Brasil em 2018, com a eleição de Bolsonaro, amparado pela ala evangélica da política brasileira. Já no Zero Hora (2019), a discussão foi a categoria do filme: afinal, Divino Amor é uma distopia ou uma utopia? Para a análise do jornal, depende de quem está percebendo o filme. De acordo com Sorlin (1986), o cinema é uma experiência coletiva e pessoal ao mesmo tempo, uma vez que a mesma mensagem pode ser interpretada de diversas formas pelo espectador, dependendo de variáveis relacionadas às suas questões pessoais. Sendo assim, Divino Amor é encarado como uma distopia, sendo que é impensável um futuro positivo no qual a religião paute o cotidiano das pessoas e a 
estrutura burocrática de um país, e uma utopia, cenário perfeito para Joana, que representa uma parte da população brasileira. Outras análises mostram o filme como uma distopia diferente das clássicas, nas quais o protagonista entre em conflito direto com o status. No caso de Joana, para a crítica realizada no Estado de São Paulo (2019), ela quer reforçar a fé e as estruturas que dominam as relações sociais e políticas no Brasil em 2027. Porém, tais inferências não levam em consideração que a personagem, de fato, luta contra o status vigente, uma vez que rompe com os preceitos ao parir um filho sem pai, renegado pela sua religião e sem registro para o Estado, representando um sinal de rebeldia e resistência, dentro da lógica da fé de Joana e do funcionamento do país.

\section{Considerações finais}

O cinema é um produto da sociedade contemporânea que desenvolve, por meio de seus conteúdos aparente e latente, histórias atreladas às questões da sociedade vigente, ganhando repercussão entre os espectadores e a impressa especializada. Nesse sentido, a compreensão da conjuntura política atual dos países em que os filmes foram produzidos se fez necessária para sua análise e a atenção para o impacto causado por eles nas mídias.

A religião está ligada à política no Brasil, Chile e Paraguai. Os três países possuem uma base religiosa muito presente em cargos públicos. A ala evangélica, que conduz a "Bancada da Bíblia" no Brasil, está presente em cargos estratégicos no país, como a comissão de Direitos Humanos e o Ministério da Mulher, da Família e dos Direitos Humanos e, desde a constituinte, lança candidatos a diversos cargos públicos, além de se fortalecer a partir de alianças com o poder executivo, uma vez que, desde 2002, os evangélicos formam alianças com os candidatos vencedores das eleições presidenciais. No Chile, a presença de evangélicos é reduzida, mas há muitos deputados católicos que, a partir de suas diretrizes, pressionam o governo a retardar alguns processos, como a demora da aprovação da Lei de Identidade de Gênero pelo atual presidente, membro da Renovação Nacional, partido que defende em seus princípios a família tradicional e se 
manifesta contrário ao aborto 9 . No Paraguai, há grande presença de católicos nos cargos públicos, culminando na eleição de Fernando Lugo, ex-bispo. Além disso, o principal partido, Colorado, tem como bases a crença em "Deus, amor à pátria e à família"10. Conforme analisado, há relatos de pouca diversidade religiosa e respeito à liberdade de crença, uma vez que há ritos católicos em diversas etapas do serviço público, como no setor educacional (ABC COLOR, 2019).

As produções analisadas se apropriaram e oportunizaram o debate sobre questões da pauta política dos países, pois, em três filmes analisados, houve repercussão negativa nas esferas Legislativas e Executiva: no Paraguai, As Herdeiras foi criticado por tratar de uma história de um casal de lésbicas; no Chile, houve pressão sobre a discussão em torno de Lei de Identidade de Gênero devido ao alcance de Uma mulher fantástica; e no Brasil, a sátira religiosa do Porta dos Fundos foi censurada pelo poder judiciário e criticada por deputados no Congresso Nacional, além de ter ocasionado um ataque ao grupo responsável pela produção do média-metragem. O último filme analisado não gerou repercussão nesse âmbito, apesar de apresentar críticas a um modelo sócio-político pautado na religião.

A questão religiosa é um dos elementos que baseiam boa parte das críticas contra os filmes analisados. A homossexualidade e a transexualidade quebram com o padrão tradicional da família sob os moldes das religiões cristãs, central para os partidos conservadores na América Latina. As Herdeiras, Uma Mulher Fantástica e A primeira tentação de Cristo abordam de formas distintas questões próximas relacionadas à quebra do paradigma tradicional da família, que enfrenta diferentes reações, mas possuem discursos parecidos: desqualificando as "lésbicas", como a senadora paraguaia Zulma Gómez; criticando o posto de "mulher fantástica", como o advogado conservador Henry Boys, que afirmou nas redes sociais que "A única mulher fantástica é mulher e foi a mãe

\footnotetext{
9 RENOVACIÓN NACIONAL. Declaración de Principios de Declaración Nacional. Disponível em: https://www.rn.cl/principios-rn/ Acesso em 20 abr 2020.

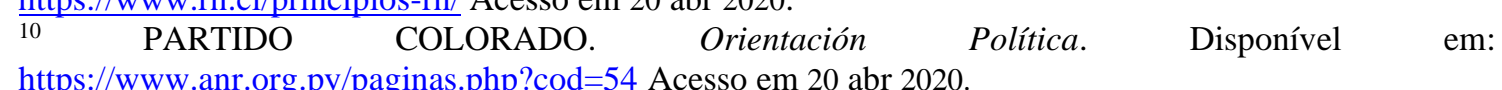
https://www.anr.org.py/paginas.php?cod=54 Acesso em 20 abr 2020.
} 
de Cristo" (LOEB, 2018), bem como desqualificando a produção, a partir de ameaças e processos judiciais e políticos, como no caso da produção brasileira.

Há de se destacar a diferença na abordagem das reportagens entre os blocos de filmes analisados no artigo. No primeiro, que trata da questão relacionada ao gênero, há maior incidência de críticas de lideranças políticas noticiadas, enquanto o longametragem que desenvolve um "mundo ideal” cristão possui críticas especializadas em relação ao roteiro e direção, mas não há ocorrências de questionamentos por políticos, tampouco tentativas de interrupção da exibição do filme. Nesse sentido, para os grupos conservadores no Brasil analisados, é aceitável um casal infeliz, que se baseia em uma fé que defende o compartilhamento do amor (troca de casais sob regras) para salvar seu relacionamento, mas não é possível a discussão e valorização das questões de gênero no cinema. As lésbicas e transexuais não podem ter um papel de destaque na história. Um Jesus gay é proibido e imoral, embora a imagem de Jesus bêbado e festeiro tenha sido bem aceita.

Retomando a tese de Gamucio (2012), os grupos religiosos têm em comum a crítica ao aborto e ao matrimônio homossexual, algo que é retratado principalmente no filme paraguaio, mas a questão da sexualidade é debatida no longa-metragem chileno e no média-metragem brasileiro. Portanto, as críticas possuem um formato comum, baseadas na defesa da família tradicional cristã e no ataque aos homossexuais. No caso da produção do Porta dos Fundos, ao fazer de Jesus um homossexual, em data próxima ao Natal, a comunidade evangélica e católica se uniram para criticar o filme, culminando com as represálias jurídicas e atentados ao grupo.

Portanto, as histórias apresentadas, bem como suas críticas veiculadas nas mídias, nos mostram qual é o modelo dos grupos conservadores dos países analisados: uma pauta política religiosa, defensora da família tradicional cristã, em que não é possível aceitar novos modelos de casais, mas que defende a manutenção de relacionamentos instáveis, desde que estejam dentro dos preceitos cristãos. Nesse sentido, o cinema denuncia a atual política praticada nesses países: seja relativizando um "mundo ideal" cristão por meio de 
críticas sutis, remontando passagens bíblicas com outros tipos de linguagem, apresentando um casal homossexual e exaltando o transsexual, os filmes debatem as questões contemporâneas das sociedades brasileira, chilena e paraguaia, divididas entre os avanços nas discussões de gênero e crenças religiosas em determinados setores, com a defesa de aspectos morais, principalmente pelas lideranças políticas católicas e evangélicas.

\section{Referências Bibliográficas}

\section{Fontes:}

As Herdeiras (Las Herdereras, Marcelo Martinessi, Paraguai, 98 min).

Uma mulher fantástica (Una mujer fantastica, Sebastian Lelio, Chile, 2017, 104 min).

A Primeira Tentação de Cristo (Rodrigo Van der Put, Brasil, 2019, 46 min).

Divino Amor (Gabriel Mascaro, Brasil, 2019, $101 \mathrm{~min}$ ).

ABC COLOR, 21/03/2019. Para recordar: Paraguay no es um estado laico. Disponível em: https://www.abc.com.py/especiales/fin-de-semana/paraguay-no-es-un-estado-laico1797635.html Acesso em 15/04/2020.

BBC News Brasil, 08/01/2020. Os argumentos do juiz que mandou Netflix suspender especial de Natal do Porta dos Fundos. Disponível em: https://epoca.globo.com/sociedade/os-argumentos-do-juiz-que-mandou-netflixsuspender-especial-de-natal-do-porta-dos-fundos-24178425 Acesso em 15 jan 2020.

CALGARO, F; MAZUI, G, G1, 10/07/2019. Bolsonaro diz que vai indicar ministro "terrivelmente evangélico" para o STF. Disponível em: https://g1.globo.com/politica/noticia/2019/07/10/bolsonaro-diz-que-vai-indicarministro-terrivelmente-evangelico-para-o-stf.ghtml Acesso em 15 jan 2020.

CORREIO BRAZILIENSE, 11/06/2018. Burocracia: setor público leva 5,5 horas para realizar único procedimento. Disponível em: https://www.correiobraziliense.com.br/app/noticia/economia/2018/06/11/internas_econ omia,687669/burocracia-setor-publico-leva-5-5-horas-para-realizar-unicoprocedime.shtml Acesso em 20 abr 2020.

Direito News, 13/12/2019. Ação judicial: juiz quer processar Netflix por vídeo do "Porta dos Fundos". Disponível em: https://www.direitonews.com.br/2019/12/jui-processarnetflix-porta-fundos-direito.html Acesso em 15 jan 2020. 
ESTADO DE MINAS, 12/12/2019. Deputado federal quer explicações da Netflix sobre especial do Porta dos Fundos. Disponível em: https://www.em.com.br/app/noticia/politica/2019/12/12/interna_politica,1107758/deput ado-federal-quer-explicacoes-da-netflix-sobre-especial-do-porta-d.shtml Acesso em 15 jan 2020.

EL PAÍS, 13/11/2017. O "Bolsonaro" chileno que louva Pinochet e quer ser presidente. Disponível em: https://brasil.elpais.com/brasil/2017/11/13/internacional/1510527795_264102.html Acesso em 15 abr 2020.

Henry Boys Loeb. https://twitter.com/realHenryBoys/status/970635130992766977 Acesso em 15 jan 2020.

La Cooperativa, 08/03/2018. Piñera: Avanzar em Ley de Identidad de Género sí, pero no para menores de edad. Disponível em: https://www.cooperativa.cl/noticias/pais/presidente-pinera/pinera-avanzar-en-ley-deidentidad-de-genero-si-pero-no-para-menores/2018-03-08/000337.html Acesso em 15 jan 2020.

MANSQUE, William. Zero Hora, 27/06/2019. Swing gospel e doutrina evangélica: filme "Divino Amor" imagina o Brasil de 2027. Disponível em: https://gauchazh.clicrbs.com.br/cultura-e-lazer/cinema/noticia/2019/06/swing-gospel-edoutrina-evangelica-filme-divino-amor-imagina-o-brasil-de-2027cjxez6p9401jg01pkxzz5opwi.html Acesso em 20 jan 2020.

R7, 11/12/2019. Abaixo-assinado pede veto de especial do Porta dos Fundos. Disponível em: https://entretenimento.r7.com/famosos-e-tv/abaixo-assinado-pede-veto-de-especialdo-porta-dos-fundos-15122019 Acesso em 15 jan 2020.

R7, 17/12/2019. Bolsonaro participa de culto de Ação de Graças no Planalto. Disponível em: https://noticias.r7.com/prisma/r7-planalto/bolsonaro-participa-de-culto-de-acao-degracas-no-planalto-17122019 Acesso em 15 jan 2020.

RODRIGUEZ, Andres. El País, 09/02/2019. “Divino amor”, una alegoria de un Brasil futurista, conservador y evangélico. Disponível em: https://elpais.com/cultura/2019/02/09/actualidad/1549670515_902678.html Acesso em 20 jan 2020.

SOMOSGAY https://twitter.com/SOMOSGAY/status/976844737889087489 Acesso em 15 jan 2020. 
ULTIMA HORA, 16/03/2019. El cine paraguayo afina su mirada para empezar a definir una identidad propria. Disponível em: https://www.ultimahora.com/el-cine-paraguayoafina-su-mirada-empezar-definir-una-identidad-propia-n2807369.html Acesso em 10 jan 2020.

ULTIMA HORA, 22/06/2018. Bochornosa actitud de senadores en condecoración a Las Herederas. Disponível em: https://www.ultimahora.com/bochornosa-actitud-senadorescondecoracion-las-herederas-n1139333.html Acesso em 15 jan 2020.

\section{Bibliografia:}

ADORNO, T. W; HORKHEIMER, M. A indústria cultural: o esclarecimento como mistificação das massas. In: Dialética do esclarecimento. Rio de Janeiro: Jorge Zahar, 1986.

BENJAMIN, Walter. Obra de arte na era da reprodutibilidade técnica. In: Obras escolhidas. São Paulo: Brasiliense, 1985.

BOAS, Taylor C. Expanding the Public Square: Evangelicals and Electoral Politics in Latin America. In: KAPISZEWSKI, Diana; LEVITSKY, Steve; YASHAR, Deborah J. The Inclusionary Turn in Contemporary Latin America. New York: Cambridge University Press, 2020.

BUTLER, Judith. Regulações de gênero. In: Cardenos pagu, n. 42, 2014.

FERRO, Marc. Cinema e História. Rio de Janeiro: Paz e Terra, 2012.

FURHAMMAR, Leif \& ISAKSSON, Folke. Cinema \& Política. Rio de Janeiro: Paz e Terra, 1976.

GUMUCIO, C. P. Religión, cultura y política en América Latina: nuevos enfoques. In: Religión, Política y Cultura en América Latina: Nuevas Miradas. Chile: Instituto de Estudios Avanzados/Universidad de Santiago de Chile, 2012.

JUNIOR, A. G. C. A; TROVÃO, F. V. B. História das Américas através do Cinema. Curitiba: Prisma, 2018.

LACERDA, Fábio. Pentecostalismo, Eleições e Representação Política no Brasil Contemporâneo. Tese de doutorado. São Paulo: Universidade de São Paulo, 2017. 
LAPSKY, Igor. Blockbusters conservadores: política e cinema norte-americano em perspectiva cruzada no tempo presente (1992-2012). Tese de doutorado. Rio de Janeiro: Universidade Federal do Rio e Janeiro, 2014.

MELO, Sydnei. Deus, a Bíblia e os evangélicos na Constituinte (1987-1988). In: Revista Caminhando, v. 23, n. 2, 2018.

MORIN, Edgar. Cultura de Massas no século XX - o espírito do tempo. São Paulo: Forense Universitária, 2018.

NOVOA, Jorge, FRESSATO, Soleni, FIELGESON, Kristian (orgs). Cinematógrafo: um olhar sobre a história. São Paulo: EDUSP, 2009.

RANCIÈRE, Jacques. A historicidade do cinema. In: Significação, v.44, n.48. São Paulo, 2017.

ROSENSTONE, Robert. A história nos filmes, os filmes na história. Rio de Janeiro: Paz e Terra, 2010.

SADER, Emir. Latinoamericana: Enciclopédia Contemporânea da América Latina. São Paulo: Boitempo Editorial, 2006.

SCOTT, Joan. Os usos e abusos do gênero. In: Projeto História, n. 45. São Paulo, 2012.

SEMÁN, Pablo. ¿Quiénes son? ¿Por qué crecen? ¿En qué creen? Pentecostalismo y política em América Latina. In: Nueva Sociedad, n. 280, 2019.

SILVA, F.C.T (org.). Dicionário crítico do pensamento da direita: ideias, instituições e personagens. Rio de Janeiro: Campus, MAUAD, 2000.

SORLIN, Pierre. Sociología del cine: La apertura para la historia de mañana. México: Fondo de Cultura Económico, 1992.

VIRILIO, Paul. Guerra e cinema: logística da percepção. São Paulo: Boitempo, 2005. 